cases her husband must have carried the infection into their home either by his clothes or in his hair.

I may add that the Liverpool outbreak did not occur in the slums of Liverpool but in a good-class locality and the only other theory of its origin besides the Glasgow infection was that a policeman who lived with the mother and daughters who first sickened of plague might have been the carrier of the infection, for he was employed at the mortuary at Princes Docks. Against this theory was the fact that there was not even a shadow of a suspicion that the said policeman had bandled a body of anyone who had died from plague.

At the end of October, 1901, there was a recrudescence of plague in Glasgow, four patients being found in the Central Station Hotel, while other two in association with them sickened of the same disease. These cases were well known to the public and I believe that a connexion was traced between them and Mr. Murdoch's cases. From then up till August, 1907, I am not aware of any cases of plague occurring in Glasgow. During the past three months (August, September, and October) there has been another recrudescence of plague in the city. There is a difference of opinion about the number of cases. The Health Department of the city only admit the existence of two cases, while in my opinion there have been nine cases, and of these five were children who died from septicæmic plague. In a subsequent issue of THE LANCET I shall publish full clinical notes of these cases along with my reasons for considering them plague. This second recrudescence of plague simply confirms our modern experience of the disease, that when it attacks a community it has a tendency to linger and to recur in the said community. Another important fact is that my cases in 1900 occurred in the latter half of August, Mr. Murdoch's cases and my case that infected Liverpool occurred in the latter half of August 1901, while the first case of the latest recrudescence occurred in the latter part of Angust, 1907, thus bearing out what Simpson has stated that plague recurs in the same locality at the same season of the year, and even in epidemics, while sporadic cases may occur all the year around; the wave of epidemicity reaches its height at a particular season of the year for each particular locality. The practical value of this observation is to be specially on the alert for plague at the season of the year it first appeared in any community.

A few remarks on the infectivity of plague in Great Britain in the light of our modern experience of it may not be out of place here. When the second outbreak of plague took place in Glasgow in $1901 \mathrm{I}$ wrote an article for the Glasgon Herald on the infectivity of the disease so as to allay the public mind. In that article I pointed out that in the original outbreak in 1900 there was not the shadow of a doubt that plague was in the city at least three weeks before its presence was suspected or even dreamt of. During that period a whole population of 800,000 were exposed to its infection, yet the net result was only 36 cases. In the Central Station Hotel outbreak the three servants were ill for several days before the disease was detected, and 200 employees and 300 guests were exposed to the infection yet the net result was six cases. In the Liverpool outbreak in 1901 the family with typical buboes were ill five weeks before detection and the whole city of 700,000 inhabitants were exposed to infection, yet the net result was nine cases. In an outbreak in Leith in May, 1905, for an official report of which I am indebted to Dr. W. Robertson, the four patients were ill for several days before the true nature of the disease was diagnosed, yet the net result was only four cases confined to one family.

I have observed some striking instances of immunity to plague. In one of my cases in 1900 a young woman was ill with plague for 18 days before I was asked to see her During that time her mother, who was 58 years of age, slept with the plague patient, ate the food that the plague patient was nnable to eat and which was handled by the plague patient, and for the whole 18 days there was the most intimate contact between the mother and her plague-stricken daughter, for they occupied a single apartment, yet the mother never sickened of plague and died five years later from a simple pneumonia. In the Liverpool outbreak, while the two girls were evidently immune to direct infection while in Glasgow and immune to the contagion they carried with them to Liverpool, yet the said contagion was able to infect their mother and she must then have developed a more virulent form of the disease, for it infected both girls and caused the death of one of them. Many similar examples could be cited and this brings out the fact that immunity to plague, like immunity to any of the group of infectious diseases, depends on conditions, the exact nature of which we have yet to solve, for plague may evidently at one time be so harmless that we could play with it, while at other times it may be most virulent, dealing death all around. It is this fact that has no doubt led Simpson to write these weighty words, which should be pondered over by every physician and especially by those in the public health service: "There is one feature of the present pandemic of plague that presages danger in the future. It is that notwithstanding its apparent inability to cause in one place a great epidemic it exhibits in some places marvellous powers of recrudescence and resistance to all known measures of prevention, and this even when the cases are few. This tenacious capacity, combined with its transportability, makes it formidable because its slow progress, few cases, and possibly slight mortality accustom the people to its presence and lull the anthorities into a frame of mind of looking upon it as a disease that can be easily controlled. In the meantime it gradually dots itself over different parts of the country, securing a n̂rm hold in some localities which again form fresh centres for its activity until in the course of a few years it is firmly established in the country at many centres and only awaits the conditions necessary for its development into an alarming epidemic."

Glasgow.

\section{A NOTE ON THE MORPHOLOGY OF SPIROCHATA DUTTONI.}

By the late J. EVERETT DUTTON, M.B. Vict., AND

JOHN L. TODD, M.D. MCGILL,

ASSOCIATE PROFESSOR OF PARASITIC PROTOZOOLOGY, MCGILI UNIVERSITY.

(From the Expedition of the Liverpool Sohool of Tropical Medicine in the Congo, 1903-04-05.)

BREINL (1), ${ }^{2}$ in the current number of the Annals of Tropical Medicine and Parasitology, describes the variations in the morphology of Spirochæta Duttoni observed during the experimental study of that parasite made at the Runcorn laboratories of the Liverpool School of Tropical Medicine (2). His description is based upon the examination of dried and fixed preparations of blood and of organ juices of infected animals stained by Giemsa's modification of Romanowsky's method; films fixed while still wet were not found to show more detail. In his paper many new points are brought forward and antecedent observations made by others and by ourselves (3) are confirmed and completed. The first part of the present note is, with the exception of a few additions, an abstract of Breinl's paper.

Spirochæta Duttoni is ribbon-shaped on transverse section. Though often wound in spirals it may be simply waved and bence may lie wholly in one plane; this can often be demonstrated in motionless parasites in fresh preparations. The spirochrta consists of a central core which stains a deep red and a surrounding periplastic sheath which stains a light pink (4). Both ends of the parasite are pointed, but one end (rarely both), through an extension of this sheath, is often prolonged into a flagellum-like process from which the central core is absent. No suggestion of peritrichal flagella (8) has ever been seen (4). The central core, or chromatic part, of the parasite frequently does not stain uniformly but shows more or less numerous irregularlyplaced, unstained areas occupying the whole breadth of the parasite $(5,6,7)$. Sometimes, especially in preparations taken just as the parasites are about to disappear from the blood, this fragmentation proceeds until the whole chromatic core is broken up into irregular granules; a clear area, of

1 A paper read before the Society of Tropical Medicine and Hygiene on Nov. 15th, 1907. This note communicates the results of the last on Nov. 15th, 1907. This note communicates the results of the last dea In reme of his death. In real which his thirtieth dis the bith year; in rement capacity for usefulness capacity for usefuness.-J. L. T. bibliography at the end. 
probably another nature, occurs quite constantly at the junction of the middle and a terminal third of the spirochæta. ${ }^{3}$ The areas lying between the granules are usually unstained but may be coloured blue.

Spirochætæ frequently occur which possess either median or terminal knob-like swellings (7). Both median and terminal swellings stain red, though the latter are occasion. ally bluish, and both often contain granules of a dense red colour. A swelling in either situation is sometimes placed laterally and definitely outside the parasite, though still attached to it by a pink-staining band. Besides the usual slender parasites of uniform thickness others occur which gradually enlarge, either at the middle or towards one end, to twice the usual thickness (7); some of these forms perhaps represent a stage preceding longitudinal division. A small clear area containing a bright red granule is sometimes seen towards one end of such a parasite. The spirochætæ usually occur singly but chains or groups of threes and fours are frequent. In the blood of heavily infected animals, particularly if it has been shed for some little time, the parasites run together in enormous tresses or clumped agglomerations. (In such collections the parasites with knob-like swellings occur most frequently; they are also common in blood ingested by ticks.) Occasionally a parasite is either wholly or partially rolled up into a tight coil. The spirochætæ are asually extracellular; rarely in blood taken just before a crisis they are found within both red and white (9) cells.

Perhaps the most usual method of multiplication of Spirochæta Dattoni is by transverse division. The parasites increase in length and become thinner at about the middle. This thinner area is gradually more and more drawn out until the parasites separate. Longitudinal division also occurs and seems to be most frequent at the end of an attack when the parasites are disappearing from the blood. Before dividing the parasite increases considerably in width. It then splits, commencing at one end, so that definitely $Y$-shaped forms are produced; these forms are not seen very frequently however ${ }^{4}$ It therefore seems possible that longitudinal division may not be a common method of multiplication. An appearance, which Breinl suggests may represent a conjugation, occurs very rarely in the blood. Two parasites lie side by side and touch at one cr more points. One stains a uniform red, the other is a light blue and apparently has no chromatic core but possesses a varying number of red granules placed at the spots at which the two parasites are in apposition.

Striking changes occur in parasites contained in the organs, particularly the spleen, bone marrow, and liver. In preparations taken just before a crisis, but while the blood is still swarming with parasites, many of the spirochætæ in spleen and bone marrow, rarely in the liver, are tightly coiled up. Some of them are swollen, the majority are more slender than usual and form skein-like coils which seem to become more irregular as the crisis approaches. Many of such parasites are engulfed by the phagocytes of the spleen and at the crisis the spleen cells are gorged with degenerated spirochætæ of this type. (In animals from which the spleen had been removed an analogous process took place in the liver.) A very few similarly coiled parasites undergo a remarkable change. They may be much fragmented or may retain their original outline. They lie, placed in a bluishstaining ground substance, within a definite cyst wall and so form a sporocyst-like body of about the same size as a red blood cell. These forms may be seen in the blood after all other forms have disappeared. They may undergo further changes : the outline of the coiled parasites becomes more indistinct and the chromatic core fragments until only the cyst, filled with red granules, remains. It is impossible to trace the further development of these forms in blood and organ juices stained by Romanowsky's method because of their great likeness to blood platelets. In the blood and organs of infected animals, and also in the blood contained in the alimentary canal of ticks, blue bodies, about $3 \mu$ in diameter (in the tick as small as $1 \mu$ ) with red central granules constantly occur. Of their nature we can say nothing save that we could identify them with no normal structure.

In only one particular have our observations led us to

3 Breinl thinks that this may represent the site of fission in a future transverse division of the parasite

$4 \mathrm{Y}$-shaped forms were particularly numerous in the juice obtained by splenic puncture just at the end of an attack in a patient who died from the disease. conclusions in disaccord with those reached by Breinl. We believe that a certain appearance, also noted by Leishman (10), definitely shows the presence of an undulating membrane in some, not all, of the spirochætæ. Breinl maintains that the appearance is merely an illusion produced by the flattening of the spiral organism on the slide. The question can only be definitely settled by the indisputably obvious demonstration of the membrane by some special technique superior to that employed by us. We have seen what we believe to be an unmistakeable undulating membrane in spirochætæ in blood taken directly from the circulation of men and animals and in blood from the alimentary tract of ticks (Ornithodorns moubata) previously fed upon infected mammals. The blood was examined either dried, fixed and stained by Romanowsky's method, or fresh in moist preparations. Some of the moist preparations were examined at once; to others varying strengths of saline solutions, tinted with neutral red, were first added; with others a weak solution of gelatine was mixed in order to retard the movements of the parasites. By each of these methods the undulating membrane has been demonstrated in either dead or living parasites. It is not seen in every spirochæta although it can usually be found in some parasites in every slide examined. It is perhaps most easily seen in dying parasites which have been injured by the addition of a salt solution of unaccustomed density to the blood containing them; in some such injured parasites the membrane can be seen hanging, partially free. Perhaps for a similar reason it was also very well seen in blood from the gut of ticks. In any case it is only by the most careful examination of specimens with the highest powers ${ }^{5}$ that the membrane can be perceived. When it occurs it runs the whole length of the body and it is occasionally manifest that some of the unstained areas in the spirochæata are due to the fact that it remains unstained at the points where its body is crossed by the membrane.

Various circumstances have prevented us from making an exhaustive study of the changes undergone by Spirochæata Duttoni in Ornithodorus moubata. Many preparations, made at various periods after the infecting feeds, of material from different parts of the bodies of infected ticks have nevertheless been examined. The appearances we mention were noted in preparations of either alimentary canal (usually receptaculum) or Malpighian tubules. We merely record our observations and do not attempt to give a complete account of the development of the spirochæta.

Besides obviously degenerating parasites all the variations in form seen in infected animals also occur in the tick. The parasites in blood from the receptaculum, which was ingested 24 hours previously, are differentiated into two more or less distinct types-one slender, the other stout. Besides these two types a third form, a huge parasite of twice the usual length and thrice the usual breadth, is seen occasionally. Parasites, usually coiled within white and red cells of the ingested blood or within the lining cells of receptaculum or tubule, are not infrequently seen. The coiled skeins and encysted forms are frequent. The most marked feature of the spirochætæ in the tick is, however, the extraordinary number of ways in which their chromatin may be fragmented. Parasites of all types without exception are affected. The granulations may be either coarse or fine. In one or two instances the granules of a finely fragmented, extracellular parasite are divided transversely so that its chromatin is represented by a row of paired granules. The granules of the encysted parasites are usually single. In others, perhaps at a more advanced stage, they are donble, and the parasite then consists of a faintly blue or reddish spherical matrix about 5 to $7 \mu$ in diameter, in which are embedded perhaps a score of pairs of deep red granules. Many such bodies have been seen in preparations from the Malpighian tubules of an infected tick. The further development of these bodies is problematical ; it is certain that some of them burst and that their granules are thus freed. In stained specimens it is apparently possible to trace the development of each single granule to a comma-shaped mass of chromatin and of these comma forms to small spirochatx. This possible development must, however, be confirmed by the continuous obeervation of fresh specimens. Breinl recalls the fact that blood which contained spirochætæ is still infective after it has been passed through a Berkefeld filter. He surmises that this may be explained by the presence of the granules described above and he suggests or 27 . 
that the above cycle of development, which we think occurs in the tick, may also take place in the mammalian host.

While many of the appearances described remain unexplained it seems possible from our observations to draw the following tentative conclusions concerning the development of this parasite. 1. Spirochreta Duttoni may multiply by direct division, longitudinally or transversely. 2. It may possibly multiply also by a process in which the fragmented chromatin of an encysted parasite is extruded in granules, each of which may subsequently develop into a new spirochata.

Bibliography.-1. Breinl: The Morphology and Life-history of Spirochæta Duttoni, No. 3, Annals of Tropical Medicine and Parasitology. 2. Breinl and Kinghorn: An Experimental Study of the Parasite of the African Tick Fever (Spirochreta Duttoni), Memoir XXI of the Liverpool School of Tropical Medicine. 3. Dutton and Todd: The Nature of Human Tick Fever in the Eastern Part of the Cong? Free State, Memoir XVII. of the Liverpool School of Tropical Medicine. 4. Stephens: A Note on the Structure of Spirochrta Duttoni, THE LANCET. August 18th, 1906, p. 438. 5. Perrin : A Preliminary Communication on the Life-history of Trypanosoma Balbianii, Proceedings of the Royal Society, London, Series B, vol. 1xxvi., p. 368. (A very suggestive similarity will be seen to exist between some of the forms described by this author and those seen in Spirochæta Duttoni.) 6. Dutton, Todd, and Tobey : Concerning Certain Parasitic Prot ozoa observed in Africa, Memoir XXI. of the Liverpool School of Tropical Medicine. (A similar fragmentation is described in a spirochæta found in a wound.) 7. Carter: The Presence of Spirochrta Duttoni in the Ova of Ornithodorus Moubata, Annals of Tropical Medicine and Parasitology, vol i., No. 1, p. 155. 8. Zellnow : Giesseln bei Hiihner und Recurrens-spirochaeten, Deutsche Medizinische Wochenschrift March 8th, 1906. p 276. 9. Novy and Knapp: Studies on Spirillum Obermeieri and kelated Organisms, Journal of Infectious Diseases, vol. iii., No. 3, 1906. 10. Leishman: Spirochætæ of Relapsing Fever and Tick Fever, THE LANCET, March 23rd, 1907, p. 806.

Runcorn.

\section{ON A VERY SUCCESSFUL METHOD OF TREATING ACUTE AND CHRONIC SUPPURATIVE OTITIS MEDIA AND OTHER FORMS OF OTORRHCEA.}

WITH A SERIES OF CASES.

BY A. F. BLAGDON RICHARDS, M.D., B.C. CaNTaB., AURAL SURGEON, SWANSEA GENERAL HOSPITAL.

IT is hardly necessary to point out how prevalent cases of otorrhcea are in practice and how frequently they stubbornly resist all treatment, persisting for years, proving a source of inconvenience and arnoyance to those thus afflicted, pro ducing marked impairment of the hearing, and too of ten giving rise to fatal complications or to symptoms demanding an immediate and severe operation. These considerations have prompted me to place before you a method of treatment that I have practised for many (about ten) years, a method by which many cases of suppurative otitis media, eren of long standing, may be recovered from completely withont operative treatment and in nearly all instances beneficial results may be obtained. Indeed, I may say that during the many years I bave been in charge of the ear department of Swansea General Hospital no cases have yielded more generally gratifying results than those of otorrbcea.

Before describing this treatment I will consider the usual course of cases of acute and chronic suppurative otitis media, speaking of them together because the one is simply the initial stage of the other. Chronic suppuration is, in fact the sequel of an acute suppuration that has not been treated or that bas baffled treatment.

The acute suppuration may start as a sequela of any of the exanthemata, more especially scarlet fever, or it may follow any inflammatory condition of the pharynx. It may start after exposure to cold and sometimes after sea-bathing. Occasionally patients originate the disease themselves by accidentally puncturing the membrane in an endeavour to clear wax out of the meatus. There is an acute inflarmmation of the tympanum and probably of the Eustachian tube and antrum as well, quickly giving rise to a serous exudation which fills the cavity. Owing to the ready access of micro organisms along the Eustachian tube the exudation soon becomes purul nt and as the tension increases the tympınic

1 Abstract of a paper read before the Swansea Medical Society on March 25 th, 1907 . membrane gives way and the pus oozes through the perfora tion into the meatus and is discharged. Too often, however, this drainage through the perforation is quite inadequate and as a result of the irritant nature of the retained fotid and decomposing pus the inflammation persists in a less acute form and the lining membrane has no chance of recovering its former healthy condition. I wish to lay stress upon the fact that the chronic suppuration does not result from any specially virulent character of the initial acute inflammation but rather from a reinfection and decomposition of the pus retained in the ear owing to the difficulty of drainage and antisepsis.

It is a matter of every-day experience that pus will not drain away completely from the meatus, even if the head be inclined over to that side, and that it has to be swabbed or washed out. How much less likely then must it be that the middle-ear cavity with its irregular surface and recesses will empty itself even if there be a free incision in the membrane or a large perforation. An incision in the membrane kefore perforation has taken place will relieve pain and tension and will facilitate drainage, but it certainly cannot be relied upon to produce complete evacuation in the tympanum and much less so if the antrum be affected. Paracentesis requires a certain amount of dexterity and practical experience in the examination of the ear to do properly and without injury, and in children at least, in whom the condition so frequently occurs, a general anæsthetic is necessary. To carry it out at the right moment the patient must be frequently seen and examined and afterwards the incision has to be prevented from closing too quickly. When a case of acute suppuration has persisted for some weeks notwithstanding the treatment adopted and has passed into the chronic condition if the egress of the pus be difficult and if there be any degree of tension then changes for the worse very quickly supervene and serious symptoms may arise demanding an immediate operation for their relief. Erosion of the lining membrane, caries, and even necrosis of the surrounding bone quickly follow the retention of offensive pus at any degree of pressure and the most serious complications may at any time become manifest.

But, fortunately, these cases are the exception and the majority run a much more chronic course, going on for years without giving rise to any urgent symptoms. In these cases the conditions are such that the pus drains away sufficiently freely for there to be no tension, but never quite completely, so that its irritant action prevents the mucous membrane from regaining a healthy condition and checks all repair. The bulk of patients met with are of this class with a chronicity varying from a few months to 20 or even 30 years and suffering solely from the inconvenience of an offensive discharge and defective hearing, with a condition, however, at all times offering a grave menace to health.

Since taking charge of the ear department of this hospital 11 years ago I have used a variety of antiseptic douches and the insufflation of antiseptic powders without a satisfactory result. The instillation of preparations of carbolic acid and the salts of mercury appeared to be too irritating if used sufficiently strong for the purpose in view and peroxide of hydrogen was disappointing. Many other antiseptics for instillation were tried without much effect in modifying the disease until I commenced using a concentrated solution of boric acid in glycerine and rectified spirit of wine, when I immediately began to have greatly improved results. Saturated aqueous solutions I had already tried for douching and instillation and also aqueous solutions with glycerine and rectified spirit in varying proportions, but the antiseptic effect was not sufficiently marked. By using glycerine as a solvent a far greater degree of concentration and activity could be obtained. I found that the addition of rectified spirit increased the solubility of the boric acid, although that substance is not so soluble in alcohol alone as in glycerine. The formula eventually arrived at was as follows: boric acid 1 drachm, rectsfied spirit of wine 2 or 3 drachms, and glycerine to make ap 1 ounce.

Although I have consulted many works on the subject of otorrhœi I have not been able to find any mention of boric acid used in this degree of concentration and combination with glycerine and alcohol for instillation into the ears. In chronic cases I have found nothing approaching this solution in efficiency It is non-irritant and non-toxic and can be used for long periods without producing any unpleasant effects. It is prolonged in action owing to the larye amount of boric acid present and also to its solution in glycerine. There is one feature about it that will partly explain its 